\title{
DO DIREITO À PRIVACIDADE À PROTEÇ̃̃O DE DADOS: DAS TEORIAS DE SUPORTE E A EXIGÊNCIA DA CONTEXTUALIZAÇÃO.
}

\section{DEL DERECHO A LA PRIVACIDAD A LA PROTECCIÓN DE DATOS: DE LAS TEORIAS DE SOPORTE Y LA EXIGENCIA DE CONTEXTUALIZACIÓN.}

\author{
${ }^{1}$ Melanie Claire Fonseca Mendoza \\ ${ }^{2}$ Luiz Mathias Rocha Brandão
}

\section{RESUMO}

Os direitos à privacidade e proteção de dados adquirem novos contornos e matizes em função do desenvolvimento tecnológico. O presente trabalho analisa o conteúdo essencial desses direitos buscando um suporte teórico que permita delimitar as fronteiras de suas atuações, procurando apontar as zonas de convergência e conflito. Neste sentido, examinamos as teorias das Esferas, do Mosaico e Espiral. A contextualização e a autodeterminação informativa ganham relevância no tratamento mais atual sobre esses direitos. Abordar-se-á o objeto deste estudo a partir de uma compreensão crítica de revisão da literatura, utilizando também posicionamentos da jurisprudência nacional e estrangeira.

Palavras-chave: Privacidade, Proteção de dados, Teorias de suporte

\section{RESUMEN}

Los derechos de privacidad y protección de datos adquieren nuevos contornos y matices dado el desarrollo tecnológico. El presente trabajo analiza el contenido esencial de estos derechos buscando un soporte teórico que permita delimitar las fronteras de sus actuaciones, apuntando para las zonas de convergencia y conflicto. En este sendero, examinamos las teorías de las Esferas, Mosaico e Espiral. La contextualización y la autodeterminación informativa ganan relieve en el abordaje más actual sobre estos derechos. Enfrentaremos el objeto de nuestro estudio desde una comprensión crítica de revisión de la literatura, utilizando además posturas jurisprudenciales nacionales y extranjeras.

Palabras-claves: Privacidad, Protección de datos, Teorias

\footnotetext{
${ }^{1}$ Doutoranda em Direito pela Universidade de Burgos - UBU, (Espanha). Advogada. Professora na Escola Superior da Magistratura da Paraíba - ESMA-PB, (Brasil). E-mail: melfonmen@gmail.com (Brasil)

${ }^{2}$ Doutorando em Direito pela Universidade de Sevilha, (Espanha). Procurador da Fazenda Nacional. E-mail: luiz_rbrandao@hotmail.com (Brasil).
} 


\section{INTRODUÇÃO}

"Correm definitivamente maus tempos para a privacidade." (LOMBARTE, 2015, p.67). Esta é a frase contundente de Juan Fernando Lopez Aguilar, ex-presidente da Comissão de Liberdades, Justiça e Interior do Parlamento Europeu. A globalização da informação acessada pelos meios digitais e a vertiginosa velocidade da revolução tecnológica atual suscitam uma enorme gama de desafios para a democracia e para as categorias clássicas do constitucionalismo. O Público e o Privado não mais correspondem a contextos isolados (ARENDT, 2001) e, como bem aponta a professora Cid "[...] questionamos a difícil defesa dos limites herméticos que custodiavam o íntimo/privado do público, superados hoje em dia por uma ágora virtual desespaciada que permite o trânsito e a acumulação de informações de dados pessoais de toda índole." (CID, 2014, p.34).

Em que pese esta dificuldade, persiste a necessidade da demarcação de um espaço vital onde o homem possa ser ele mesmo, livre da crítica dos demais, submetendo-se unicamente à sua própria consciência.

Em 1891, Benjamin Constant (1891 tomo II, 541), em um ensaio clássico, já dizia que a liberdade dos antigos gregos consistia no direito de participar da vida pública e que a liberdade para os modernos, no entanto, consistia no direito de refugiar-se na vida privada sem ser incomodado por ninguém. Compreender o núcleo essencial do Direito à Privacidade, seus contornos e matizes, adequando-os ao seu tempo, representa um desafio. Nessa perspectiva, a dinâmica e a flexibilidade da noção de privacidade representam traços caracterizadores que refletem a falta de precisão quanto ao conteúdo a ser protegido pelo Direito à Privacidade.

Agregado a isto, e considerando o cenário de constantes inovações no universo dos atuais meios de difusão das informações, as previsões legais sobre o Direito à Privacidade não seguem o mesmo ritmo reclamado pelas necessidades sociais. Do mesmo modo, a avalanche a que somos submetidos pelas inovações tecnológicas não nos permite um olhar suficientemente profundo e reflexivo sobre estes acontecimentos, resultando na escassez de teorias que permitam uma atuação sólida do direito.

A amplitude do Direito à Privacidade vai além do que alcança nosso olhar e suas inúmeras interações com outros direitos resultam em múltiplas manifestações que conferem a este direito seu caráter polifacético. De fato, uma parcela cada vez mais significativa de nossa 
vida privada se manifesta e se desenvolve no entorno virtual, elevando significativamente as possibilidades de danos aos nossos direitos mais essenciais (personalidade).

Tendo por base esta constatação, analisaremos, nas linhas que se seguem, o direito à privacidade e uma de suas novas facetas, o direito à proteção de dados. Estabeleceremos as relações entre ambos, ao mesmo tempo em que verificaremos as teorias de suporte que servem de substrato à proteção desses direitos. Abordaremos o objeto de nosso estudo a partir de uma compreensão crítica de revisão da literatura, utilizando também alguns posicionamentos da jurisprudência nacional e estrangeira.

\section{A GÊNESIS DO DIREITO À PRIVACIDADE}

Para Gasset (1994, p.541), existe uma necessidade inerente ao ser humano de debruçarse sobre si mesmo, de interiorizar-se e concentrar-se em si. A esse processo, ele denominou de ensimesmamento. Esse movimento permite a criação de um espaço reservado onde o homem pode desenvolver-se livremente e, de forma íntima, construir ideias, distanciando-se do mundo exterior. Em que pese a importância da privacidade apontada pelo autor, seu reconhecimento pelo Direito foi relativamente recente, de modo que não faz muito tempo que se deu o reconhecimento de que esse espaço privativo tem uma conexão umbilical com a dignidade da pessoa humana.

O primeiro passo rumo à autonomia do direito à privacidade, foi dado em 1890 pelos advogados Samuel D. Warren y Louis D. Bradeis, ao publicar na Havard Law Review o artigo "The Rigth to Privacity". Em seu estudo, expõem suas críticas sobre os perigos que as novas tecnologias poderiam representar ao ocasionar danos aos valores éticos e políticos, ao que eles decidem denominar de Direito à Privacidade. O artigo dos advogados teve como estímulo o escândalo sobre a vida conjugal de Warren, casado com a filha de um político importante.

De acordo com Warrem e Bradeis,

[...] os recentes inventos e os novos métodos de fazer negócio foram os focos de atenção ao passo que foi necessário dar amparo à pessoa e garantir ao indivíduo o que o juiz Cooley denominou de direito a não ser incomodado. As fotografias instantâneas e as empresas de jornalismo invadiram os sagrados recintos da vida privada e no lar; e os inúmeros engenhos e mecanismos ameaçam em fazer realidade a profecia que reza: "o que se sussurre na intimidade será proclamado aos quatro ventos [...]”. A intensidade e a complexidade da vida, que acompanham os avanços da civilização, contribuem para o necessário distanciamento do mundo, e o homem, sob a refinada influência da cultura, se vê mais vulnerável à publicidade, de modo que a solidão e a intimidade se converteram em algo essenciais para a pessoa; por 
isso, os novos modos e inventos, ao invadir a intimidade, produzem no indivíduo um sofrimento espiritual e uma angustia muito maior que pudera ocasionar os meros danos pessoais. (WARREN; BRADEIS, 1995 p. 196)

Apesar do texto citado haver sido publicado há mais de um século, a temática abordada ainda continua viva e latente. Se, naquela época, a grande preocupação girava em torno das máquinas fotográficas que permitiam registrar imagens a distância, hoje há outro temor centrado em instrumentos virtuais (internet) que ampliam, assustadoramente e de modo exponencial, os danos já anteriormente percebidos por Warren e Bradeis.

Resulta interessante perceber que, apesar da importância do artigo dos célebres advogados de Boston, a gênese da guarda da privacidade está no direito inglês. A ideia se origina na proteção ao domicílio frente às intromissões de qualquer pessoa, até mesmo do monarca. Deste modo, se invoca o discurso de William Pitt ante o Parlamento inglês no ano de 1763:

\footnotetext{
O homem mais pobre, em sua cabana, desafia todas as forças da Coroa, [sua cabana] pode ser frágil, seu teto talvez seja instável, o vento pode adentrar, a tempestade pode adentrar nela, não existe impedimento para que a chuva a molhe, mas o Rei da Inglaterra não pode nela entrar; nem com todo seu poder se atreve a atravessar o umbral desta ruinosa morada. (PITT, 1803. V. 15. 1307)
}

Assim, desde sua origem, a noção de Direito à Privacidade se associa a um espaço individual e protegido de intromissões externas não autorizadas.

Ao dar um salto na história e aproximar a todos no tempo, o Direito à Privacidade é amplamente reconhecido pelos mais variados Ordenamentos Jurídicos. Entretanto, o reconhecimento da existência de um direito somente tem real sentido e eficácia protetora quando a ele se atribui conteúdo, os cimentos em que se fundamenta. Nessa medida, averiguar o conteúdo essencial do Direito à Privacidade é tarefa primordial na hora de compreender seu alcance e profundidade.

\section{UMA APROXIMAÇÃO AO CONCEITO DE DIREITO À PRIVACIDADE}

A tarefa de conceituar é das mais difíceis. Ao elaborar um conceito escolhemos os elementos que desejamos enfatizar e, no mesmo instante em que o fazemos, deixamos à margem de nossa análise um sem fim de espaços da realidade. Assim, e apesar dos esforços que façamos, um conceito sempre será um olhar pela fechadura, o que significa dizer que sempre estará limitado por nossos interesses, nossas emoções e nossas possibilidades pessoais. 
No entanto, como essas variáveis são condições humanas, não podemos pretender um trabalho intelectual totalmente isento, o que significa que é imprescindível aprender a trabalhar com aquilo que o positivismo considera limitações ao conhecimento. Por outro lado, o ato de conceituar ganha status e importância já que é ele, o conceito, que nos permite uma aproximação à temática e constituir as bases sobre as quais se assenta a disciplina.

Sobre a nossa temática, percebemos um leque bastante amplo de conceitos sobre o direito à privacidade. Cada um desses conceitos evidencia algum aspecto particular deste direito. De fato, podemos dizer que, apesar dos esforços da doutrina, ainda não foram suficientemente desenvolvidos todos os seus aspectos assim como não estão dispostos em numerus clausus as inúmeras manifestações do direito à privacidade.

O direito à privacidade projeta seus tentáculos na direção de outros direitos e realidades, conectando-se com eles, produzindo um fenômeno peculiar que aumenta sensivelmente suas facetas. Estamos nos referindo, aqui, ao fio que conecta o direito à privacidade com a proteção ao domicílio e com a liberdade de pensamento só para citar alguns exemplos. Da mesma maneira, é imprescindível acrescentar que as mudanças sociais também proporcionam novas interações resultando em novos contornos à privacidade, a exemplo do que acontece com o Direito à Proteção de Dados.

Percebendo as múltiplas interações em que se pode manifestar o Direito à Privacidade, o professor da Universidade dos Andes, Talciani (2000), o conceitua como um bem jurídico em virtude do qual uma pessoa se

[...] encontra livre de intromissões ou difusões cognitivas de fatos que pertencem à
sua interioridade corporal ou psicológica ou às relações que elas manifestem ou
mantiveram com outros, por parte de agentes externos, sobre a base de uma
valoração media razoável são alheios ao conteúdo e finalidade desta interioridade ou
relação. (TALCIANI, 2000, p.4)

Ademais, desde a perspectiva de Lara: "a privacidade se vincula a uma manifestação jurídica do respeito e proteção que se deve a cada pessoa, protegendo a dignidade e a liberdade humana, por meio do reconhecimento ao seu titular de um poder de controle sobre aqueles âmbitos nos quais não participam outras pessoas.” (LARA, ano, p.).

Nos mesmos caminhos da autodeterminação informativa, encaminha-se a noção proposta por Araújo, para quem a privacidade se entende como um "conjunto de informações sobre o indivíduo em que ele mesmo pode decidir manter, sob seu exclusivo controle, ou comunicá-las, decidindo a quem, quando e em que condições" deseja fazê-lo (ARAÚJO, 1998, p.44). Aqui, percebemos que o Direito à Privacidade ganha uma nova roupagem. Nesta 
perspectiva, ele passa de um simples direito garantidor de defesa frente a intromissões externas para um direito ativo de controle. $\mathrm{O}$ indivíduo passa a ser protagonista naquilo que deseja ou não desvelar.

Por fim, e porque em tudo devemos encontrar poesia, Prosser (1960) nos apresenta que haverá ofensa ao direito à privacidade ante uma divulgação de fatos particulares molestos a um indivíduo deixando-o sob uma "falsa luz" aos olhos dos demais (PROSSER, 1960, p.383).

Buscando uma noção suficientemente ampla que ampare o objeto de nosso estudo, podemos dizer que o direito à privacidade se traduz no distanciamento do mundo exterior, não permitindo a intromissão arbitrária na vida íntima do indivíduo em seus múltiplos ambientes ao mesmo tempo em que outorga autonomia a este mesmo sujeito para administrar as informações relativas à sua vida privada.

Levando em consideração este conceito, é imprescindível aprofundarmos o conteúdo da intimidade/privacidade. Neste sentido, resultam de utilidade certas teorias que procuram uma representação analítica destes conteúdos apontando para as zonas de convergência e conflito.

\section{ENTRE A ESFERA E O MOSAICO - TEORIAS DE DELIMITAÇÃO DO ÂMBITO PRIVADO}

A busca da delimitação entre os conceitos de privacidade-intimidade culminou em teorias que, de modo objetivo, desenham os contornos deste direito fundamental.

Entretanto, antes de analisar propriamente essas teorias, é necessário entender que, diante de uma colisão entre o direito à privacidade e outros direitos em jogo, a técnica utilizada para a análise do direito à privacidade se estrutura em dois níveis de estudo. Em um primeiro momento, é necessário indagar se o objeto que se pretende proteger faz parte da substância do direito à privacidade. Sendo afirmativa a resposta a esta pergunta, passamos à segunda etapa de averiguação que consiste em indagar se a intromissão na privacidade está ou não constitucionalmente justificada por resultar do exercício legítimo de outro direito. Esta estrutura de ponderação permite traçar uma trajetória clara de diagnóstico, contribuindo para uma maior segurança jurídica no exercício do balancing test. É no primeiro nível de estudo que encontramos a Teoria das Esferas.

Inicialmente idealizada por Heinrich Hubmann (HUBMANN apud COSTA JR., 1995, p.30) e posteriormente aperfeiçoada por Heinrich Henkel, a Teoria dos Círculos 
Concêntricos da Personalidade ou Teoria das Esferas (Sphärentheorie) permite uma visualização gráfica dos direitos à privacidade e à intimidade. A vida privativa do indivíduo é concebida em camadas: Privatsphäre; Intimsphäre y Geheimsphäre; elas constituem círculos concêntricos formadores de uma mesma estrutura.

O círculo mais externo, de maior amplitude, representa a esfera do privadoPrivatsphäre. Nessa esfera estão os aspectos mais periféricos da vida de uma pessoa. É a denominada esfera social ou pública. As características que demarcam este âmbito de nossas vidas são bastante palpáveis. De acordo com o entendimento do Tribunal Constitucional alemão (BVerfGE 80, pp. 367-373), sua transparência corresponde à sua marca registrada ao mesmo tempo em que a divulgação de seu conteúdo só é impossibilitada quando se tratar de uma informação considerada falsa ou quando seja lesiva à honra.

O segundo círculo, o da intimidade - Intimsphäre - representa o espaço de nossas relações pessoais mais próximas com as quais estabelecemos um status de confidencialidade. Um exemplo de conteúdo deste nicho pode ser encontrado na jurisprudência espanhola a exemplo da decisão STS de 18 de fevereiro de 2013 (RJ 2013-2016) em que o direito à intimidade familiar objetiva garantir ao sujeito um espaço reservado que coincide com aquele em que ele desenvolve relações familiares, blindando-o do conhecimento alheio contra sua vontade. Neste sentido, podemos afirmar que se protegem aqui as situações envolvendo problemas conjugais, as crenças religiosas e os problemas de saúde. Resulta interessante observar que muitas Constituições reconhecem a vida íntima familiar como direito fundamental. Isto ocorre nas Constituições da Espanha de 1976 (art. 18.1) e na de Colômbia de 1991 (art. 15, caput), por exemplo. Este tipo de previsão não foi acolhido pela Constituição brasileira.

Mergulhando mais fundo na análise da Teoria das Esferas, chegamos ao menor círculo, o mais restrito dos três - Geheimsphäre - a esfera do segredo. Representa o âmbito da vida íntima stricto sensu. Neste pequeno espaço, estão nossos pensamentos, nossos sentimentos mais secretos sendo, em essência, um espaço salvaguardado da crítica alheia. Deste modo, esse círculo mais restrito, o mais nuclear dos três, deve gozar de um maior grau de proteção. De modo geral, os tribunais que adotam a Teoria das Esferas como marco interpretativo, blindam este espaço de qualquer tipo de intromissão. Ocorre que, na atualidade, existe uma tendência a relativizar esta ideia. Assim, apostila o professor Guerrero (2005) ao estabelecer que 
[...] se ha defendido la conveniencia de relativizar este nivel de protección, propugnándose la siguiente formula: cuanto más íntimo sea el ámbito afectado, tanto más riguroso deben ser las exigencias para justificar la medida (la intromisión); y cuanto más afectado esté el interés social, tanto más factible será proteger el interés o bien que colisione con el derecho general a la personalidad. (GUERRERO, 2005, p. 18)

Arrematando as ideias anteriormente expostas, podemos dizer que na Privatsphäre estão as informações pessoais que podem ser genericamente protegidas do domínio público. $\mathrm{Na}$ Intimsphäre, por sua vez, se resguarda da curiosidade alheia aqueles dados que somente compartilharíamos com um grupo restrito de pessoas e, mesmo assim, de modo reservado. A intimidade em sentido stricto - Geheimsphäre - (FIORI, 2012, p.4) corresponde às nossas emoções e sentimentos cujo teor não compartilhamos com ninguém e, caso isso viesse a acontecer, seria com um amigo e confidente. Em que pese a fluidez de seu conteúdo, a Teoria das Esferas é amplamente aceita por muitos Ordenamentos Jurídicos. Na Espanha, para citar um exemplo, já nos aponta Caro (2014) que o próprio Tribunal Supremo já se manifestou abrigando essa mesma ordem de ideias, destacando que "a esfera privada inclui aquele setor de circunstâncias que, sem ser segredo, nem íntimo merecem ser garantidos para o normal desenvolvimento e tranquilidade dos titulares particulares.” (CARO, 2014, p. 51).

No que se refere à legislação espanhola, na exposição de motivos da Lei de Proteção Orgânica de Tratamento Automatizado de Dados de Caráter Pessoal, Lei 5 de 29 de outubro de 1992, em seu apartado I estabelece a adoção de uma sistemática de distinção entre privacidade e intimidade.

\footnotetext{
Note-se que se fala de privacidade e não de intimidade: aquela é mais ampla que esta, pois enquanto a intimidade protege a esfera em que se desenvolvem as facetas mais singularmente reservadas da vida privada de uma pessoa, a privacidade constitui um conjunto mais amplo, mais global das facetas de sua personalidade.
}

Em suma, a intimidade corresponde ao setor sem luz da nossa personalidade, nele somente seu titular consegue transitar porque bem conhece os muitos caminhos que ele mesmo construiu; o público corresponde ao âmbito totalmente iluminado que permite que todos possam conhecer o seu teor, já o privado se caracteriza por sua meia-luz, ou seja, possui uma visibilidade reduzida.

Em particular, no caso brasileiro, vislumbra-se uma falta de consenso seja na doutrina, seja na jurisprudência quanto à necessidade ou não de distinção entre os termos privacidade e intimidade. O art. 5, Inciso X da Constituição Federal de 1988, diz: "são invioláveis a intimidade, a vida privada, a honra e a imagem das pessoas, assegurado o direito 
a indenização pelo dano material ou moral decorrente de sua violação”. Amparados na discriminação feita pela própria Constituição, alguns autores entendem pela existência de dois bens jurídicos distintos, com características diferentes (BRASIL, 1988). Por outro lado, não raro encontramos julgados em que, ao não se considerar a existência de fronteiras entre esses espaços vitais da personalidade, aplicam-se indistintamente os termos privacidade e intimidade o que supõe sua tutela de maneira uniforme.

É nessa última linha de raciocínio que se baseia a decisão do Tribunal de Justiça do Distrito Federal só para citarmos um exemplo:

RECLAMAÇÃO. MINISTÉRIO PÚBLICO. INTERCEPTAÇÃO TELEFÔNICA. DIREITO À INTIMIDADE E À PRIVACIDADE. CARÁTER RELATIVO. INTERESSE PÚBLICO. INVESTIGAÇÕES POLICIAIS. ELUCIDAÇÃO DE ESTELIONATO. PROPORCIONALIDADE.

I. o direito à intimidade e à privacidade não possuem caráter absoluto. Cede espaço ao interesse da sociedade. [...]. (BRASIL, 2009)

A fusão dos dois termos é proposta por Donela (2006):

\begin{abstract}
Os termos "vida privada" e "intimidade" fazem menção específica a determinadas amplitudes do desenvolvimento da proteção da privacidade, como a teoria dos círculos concêntricos de Hubmann (ou, como visto, da "cebola passiva"), que apresentaram maior importância em um determinado contexto e momento histórico. Aplicá-las à atual problemática dos dados pessoais, por exemplo, somente poderia ser feito com um raciocínio extensivo - o que, por si só, mitigaria os pressupostos de sua existência. Utilizar o termo privacidade parece a opção mais razoável e eficaz. $\mathrm{O}$ termo é específico o suficiente para distinguir-se de outros termos com os quais eventualmente deve medir-se, como a imagem, honra ou a identidade pessoal; e também é claro bastante para especificar seu conteúdo, efeito da sua atualidade. Mas esta escolha não surge somente da fragilidade das demais; ela revela-se por si só a mais adequada - por unificar os valores expressos pelos termos intimidade e vida privada. (DONELA, 2006, pp. 111-112.)
\end{abstract}

Esta perspectiva unificadora das acepções dos termos não tem cabimento no atual estágio de entendimento dos direitos de personalidade e as consequências diferentes de suas possíveis violações. Se os direitos são cada vez mais relativizados, é essencial a preservação de um espaço vital do indivíduo onde ele possa ser, em toda sua profundidade livre, de intromissões. Embora exista a necessidade de demarcação deste espaço e em que pese a importância que teve a Teoria das Esferas em um determinado momento, essa concepção de círculos não contempla a dinâmica de uma realidade que resiste a ser engessada.

Privacidade, intimidade e segredo são vivenciados por seres humanos que não existem fora de um momento, de uma cultura e de uma sociedade. A vida no mundo pósmoderno é de tal sorte mutável que não nos permite traçar contornos tão cartesianos, o que nos leva a afirmar a existência de uma para a demarcação científica das fronteiras existentes. 
Entretanto, resulta importante perceber dois pontos positivos da elaboração teórica proposta pela Teoria das Esferas. O primeiro se refere à tentativa de fuga da casuística, do direito elaborado no caso concreto, representando um esforço rumo ao estabelecimento de critérios objetivos que permitam, ao juiz, realizar uma ponderação orientada por parâmetros que permitam a previsibilidade das decisões judiciais. A segunda contribuição positiva está no fato de que a simples adoção da teoria das esferas leva necessariamente a aceitar um âmbito reservado do indivíduo, imune de qualquer intromissão e que tem, como característica, a sua natureza secreta.

Por outro lado, vislumbramos que a Teoria das Esferas tem como foco a informação, posicionando-a em cada uma das três esferas em função do maior ou menor grau de relevância.

Adotando um critério diferente, não baseado no conteúdo da informação mas na potencialidade que ela tem para desnudar o indivíduo de qualquer proteção a sua privacidade. Conessa (1984) elaborou uma interessante construção; a Teoria do Mosaico. De acordo com ele:

\footnotetext{
Existen datos a priori irrelevantes desde el punto de vista del derecho a la intimidad y que, sin embargo, en conexión con otros, quizá también irrelevantes, pueden servir para hacer totalmente transparente la personalidad del ciudadano, al igual que ocurre con las pequeñas piedras que forman los mosaicos, que en sí no dicen nada, pero que unidas pueden formar conjuntos plenos de significados. (1984. 44-45)
}

$\mathrm{Na}$ verdade, nem sempre estas construções mentais feitas a partir de pequenos fragmentos correspondem ao que realmente significa o indivíduo. Podemos inclusive afirmar que, muitas vezes são estas construções e deduções que nos tornam vulneráveis, ferem nossa intimidade e se constituem em violenta agressão aos nossos mais profundos sentimentos.

Fazendo uma interpretação da Teoria do Mosaico frente às novas tecnologias, se faz adequado apontar que, com os meios de comunicação atuais, foi gerada uma dinâmica diferente nas relações. Vivemos em uma sociedade em rede ou, como costumam chamar, uma Sociedade Informacional. O uso em massa da internet nas comunicações mudou brutalmente nossa percepção de tempo e espaço, além de ter um poder transformador do próprio conteúdo da informação. Esta não é mais veiculada exclusivamente por empresas de comunicação, mas também por indivíduos anônimos, de forma imediata, desde os mais remotos lugares do mundo e impregnadas das mais diversas interpretações. Esta nova sociedade tem suas bases no primado da informação. A criação e a circulação da informação constituem movimentos primordiais que contêm aspectos políticos, econômicos, jurídicos e sociais. 
A informação é, dessa maneira, o centro de nossa sociedade atual e o indivíduo está cada dia mais dependente dela. Este processo também fez com que uma parte do que somos fosse transformada em dados, signos que nos identificam no plano da existência virtual. Diferentemente do que acontece em outros meios de comunicação, a internet tem um traço que a distingue dos demais meios: possibilitar o fluxo contínuo da informação em um espaço permanentemente aberto.

Não existem limites para as atualizações, para as revisões ou para os compartilhamentos entre seus usuários.

Além disso, as ferramentas de busca, como Google, Yahoo ou Bing, para citar algumas, catalisam, cruzam e selecionam as informações, produzindo uma rede de complexidade crescente de múltiplos e imprevisíveis resultados.

A existência dessas cápsulas de informação proporcionadas pelas ferramentas de busca reforçam as ideias do professor espanhol Conessa em sua Teoria do Mosaico. Algumas vezes uma informação concebida como insignificante quando analisada isoladamente, pode no entanto, dada as possíveis relações resultantes em uma simples busca na internet, nos levar a estabelecer perfis completos (verdadeiros ou falsos) de uma pessoa.

Assim, e em virtude dos novos tempos em que vivemos, existe um clamor na direção de uma melhor proteção à privacidade. Esse novo cenário exige a construção de instrumentos normativos e doutrina que tenham como objetivo a proteção da privacidade, considerando-se a complexa realidade tecnológica em que vivemos. Nesta perspectiva, surgem novos aspectos do direito à privacidade como aqueles configurados pelos direitos à proteção de dados, ao direito de acesso e retificação e ao direito ao esquecimento, entre outros.

No mesmo fluxo destas mudanças, encontramos uma concepção dinâmica da privacidade. Se, nos primórdios, estava sólida a ideia de um núcleo duro de nossa privacidade, um âmbito hermético, cujas informações não são acessíveis aos olhares de terceiros, esta noção cede passo a uma noção ativa e dinâmica tendo como personagem principal o próprio titular do direito à privacidade. Assim, será o indivíduo quem deverá estabelecer quais e sob que intensidade de proteção devem estar as informações que lhe digam respeito. Esta é a noção de privacidade como poder de controle. Assim, se produziu uma importante mudança no conceito:

[...] antes eram os poderes públicos os encarregados de constatar os limites da intimidade, mesmo que para isso se remitissem a umas pautas culturais que lhes vinham marcadas pelo entorno social, ao estabelecer o que deveriam ou não considerar sensíveis. Agora, a intimidade parece cobrar o alcance que seu titular decida dar, à margem de toda pauta. (XIV Encuentro..., 2000-2001, pp. 48-49) 
A autodeterminação informativa corresponde a um importante passo na atribuição de responsabilidade ao cidadão para a utilização e manejo de seus dados pessoais.

Nesta perspectiva, resulta de difícil aplicação as ideias contidas na Teoria das Esferas já que ela propugna pela criação de espaços fechados onde o conteúdo da informação é o critério prevalente e onde o poder de mando do titular do direito à privacidade não é avaliado. As novas dinâmicas nas relações sociais nos indicam que este não deve ser o caminho a ser seguido.

Na mesma trajetória de mudanças impostas pelas novas tecnologias, deparamo-nos com o florescimento de um novo direito, já anteriormente mencionado, em que pese tenha sido germinado no seio do direito à privacidade e que com ele ainda mantenha relação estreita, tem, hoje, vida própria; estamos nos referindo ao Direito à Proteção de Dados do qual nos ocuparemos em seguida, buscando analisar as teorias que lhe dão suporte e suas interações com o Direito à Privacidade.

\section{DO DIREITO À PROTEÇÃO DE DADOS}

É inegável que uma parcela de nossa vida e de nossa personalidade se desenvolve no universo virtual. Cada um de nós é o resultado de um conjunto de informações, dados, senhas e elementos que, somados, nos singularizam e traçam o perfil do que somos, ou pelo menos do que acham que somos.

As inúmeras ferramentas criadas pelos avanços da tecnologia informática permitem um sem-fim de possibilidades de armazenamento, tratamento e intercâmbio de informações a respeito de tudo e de todos. Utilizando esses mecanismos, a Receita Federal do Brasil, só para citar um exemplo, realiza o cruzamento de dados como expediente para evitar ou reduzir fraudes na arrecadação de tributos. Do mesmo modo, e sem a existência do interesse público, também podemos citar as declarações do vice- Presidente da montadora Ford que, em entrevista, é taxativo ao afirmar que: "se existe um GPS em seu carro sabemos o que você está fazendo." (TERRA, 2004). A velocidade com que dirigimos o nosso carro, os lugares e trajetos percorridos, o tempo utilizado são algumas das informações que, sem nenhum pudor, são armazenadas sem o consentimento de muitos condutores. Não resulta difícil compreender o destino comercial atribuído a esses dados que, no mundo dos negócios, têm seu "peso em ouro". A tragédia deste cenário é que, na grande maioria das ocasiões, trata-se de uma captura ilícita de dados e os sujeitos nem sequer sabem de sua condição de vítima. 
Resulta impactante perceber que, na sociedade Informacional em que vivemos, os bancos de dados públicos ou privados se multiplicam a uma velocidade impressionante. Nessa perspectiva, o Estado não pode estar alheio ao potencial ofensivo do manejo desses dados, sendo imprescindível uma ação proativa dele. É neste humus que germina o direito à proteção de dados.

Nesta ordem de ideias, podemos afirmar que o direito à proteção de dados tem, por finalidade, garantir ao indivíduo um poder de controle sobre seus dados pessoais, resguardandoos de trânsito ilícito ou ofensivo a sua dignidade. Deste modo, o Direito à Proteção de Dados outorga um poder de disposição sobre esses dados a seus titulares, ao mesmo tempo em que impõe, ao Poder Público, a obrigação de zelar para que esses dados não se convertam em fontes de informação, sem as devidas garantias e sem as medidas capazes de prevenir possíveis maus usos.

Em apertada síntese, podemos dizer que o direto à proteção de dados tem a característica de possuir um objeto de proteção mais amplo que o direito à intimidade. Neste sentido, e socorrendo-nos do Tribunal Constitucional Espanhol

[...] a proteção de dados não se reduz só à proteção de dados íntimos da pessoa, mas sim de qualquer tipo de dado pessoal, seja ou não íntimo, cujo conhecimento ou uso por terceiros possa afetar a seus direitos, sejam ou não fundamentais, porque seu objeto não é só a proteção da intimidade pessoal, já que para isto já existe o direito à intimidade, e sim os dados de caráter pessoal. (STC 292/2000, FJ 6)

Resulta primordial compreender que o que se pretende com o Direito à Proteção de Dados não é blindar os dados pessoais contra qualquer intervenção mas o que se objetiva é proteger o manejo desses dados; seja permitindo uma gestão regrada, seja resguardando aqueles dados mais sensíveis do olhar curioso dos demais.

Entende-se que um dado pessoal, qualquer que seja, é, em si, merecedor de proteção com base nos ditames do direito à proteção de dados. Haverá, entretanto, ocasiões em que esse dado contextualizado - imerso no magma flutuante de outros dados obtidos no ciberespaço - possibilite a revelação de muito mais do que o indivíduo deseja ou permita revelar, sendo, nesse caso, objeto de proteção do direito à privacidade.

Levando em consideração esta realidade fática e buscando uma construção teórica que dê suporte à proteção dos direitos fundamentais envolvidos, percebe-se a falta de adequação da Teoria das Esferas dado o fato de que suas bases estão fincadas em uma análise aritmética dos elementos que compõem a vida privada. Essa teoria não dá conta de dois aspectos fundamentais na consideração da proteção. Em primeiro lugar, a autodeterminação 
do indivíduo e, em segundo, a transformação do potencial ofensivo da divulgação de um dado quando contextualizado e associado a outros dados.

A Teoria do Mosaico, por outro lado, aproxima-se mais do cenário em que vivemos hoje. Por meio dela, podemos entender a necessidade da contextualização no exame das muitas peças que nos compõem. Nenhum dado informacional vive isoladamente, ele sempre está relacionado com outros, de modo que somente vislumbrando as interações é que podemos aferir o potencial ofensivo da informação revelada.

Ainda que a Teoria do Mosaico promova uma maior aproximação da realidade, percebemos que ainda estamos longe de formular uma construção teórica que dê suporte para a proteção legal de nossos dados e da nossa privacidade em um cenário marcado por uma tecnologia que avança a passos mais largos do que os do legislador ou do doutrinador. É imprescindível que haja uma maior reflexão, uma ampliação dos horizontes que permita agregar, à edificação de uma nova teoria, noções já sedimentadas como a da autodeterminação informativa. Esta impõe um novo panorama de análise já que pouco importa o conteúdo daquilo que se deseja manter ao abrigo do conhecimento público posto que cabe, ao próprio sujeito, classificar tais informações, controlando quais e em que medida poderão ser vistas por outros. Ao indivíduo corresponde delimitar o público, o privado, o íntimo, ou apenas o pessoal, embora existam informações que, independentemente do desejo de seu titular, devam ser administradas pelo Estado em razão de determinados interesses públicos.

\section{UMA APROXIMAÇÃO TEÓRICA NOVA}

A necessidade de diferenciação entre os três âmbitos em que desenvolvemos a nossa personalidade não é um preciosismo técnico. A delimitação vai muito além do rigorismo terminológico. Como bem salientou Valdés (2003) em seu trabalho "Algunos Comentarios sobre lo íntimo, lo privado y lo público", publicado na revista Clave: "sí puede establecerse una distinción plausible entre lo íntimo, lo privado y lo público y que, en todo caso, la distinción entre lo privado y lo público es fundamental para determinar el alcance normativo de un sistema político-jurídico" (VALDÉS, 2003, p.16).

Nesta medida, compreender tais limites equivale a estabelecer as próprias fronteiras da atuação estatal ao mesmo tempo em que regula a liberdade do indivíduo. Entretanto, demarcar estes espaços não significa dizer que correspondem a recintos precintados. $\mathrm{O}$ próprio Valdés salienta, em seu trabalho, que existe uma flutuação do conteúdo de informações, seja do público ao âmbito privado, seja na direção inversa, do privado ao 
público. Se de um lado temos o próprio indivíduo, titular dos direitos como agente que, por iniciativa própria desvela seus pudores, por outro lado temos o Estado que, com base em múltiplas razões, tendo por base o interesse público, intervém neste espaço reservado controlando e gerindo as informações. Não obstante, os acontecimentos históricos mais atuais revelam uma atuação cada vez maior do Estado na privacidade/intimidade dos indivíduos sob o pretexto de dar mais segurança à sociedade. Outro agente que revela a privacidade transformando-a em dado público é o próprio titular da informação. A hiper exposição de nós mesmos revela um movimento peculiar no mundo virtual. É o próprio indivíduo que desvela suas informações mais íntimas, compartilha e comenta seus acontecimentos mais entranháveis ou que pelo menos assim deveriam permanecer. Sobre esta perspectiva, analisou recentemente o filósofo Baumman (2001, p.17), que lançou a ideia do pós- panóptico como característica da sociedade contemporânea. Em suas reflexões, Baumman traduz a liquidez em que vivemos, a retroalimentação existente entre vidas que expomos e vidas que vigiamos resultando em um esvaziamento do que somos.

Pois bem, retomando a ideia de flutuação das informações nos três âmbitos da personalidade (público, privado e íntimo); e, no intento de buscar uma teoria que se adapte ao ciberespaço e suas características, encontramos uma nova construção teórica. Estamos nos referindo à Teoria da Espiral esboçada por Cid:

\footnotetext{
El libre y doble tránsito de la información personal de unas esferas a las otras nos permite esbozar una teoría de la espiral según la cual, si bien se sigue considerando un centro de exclusión de la intromisión ajena, se ha perdido el control pleno de la información íntima y personal. Los nuevos medios tecnológicos permiten que nada quede oculto o secreto y con ello se acrecienta el peligro de vulneración de la intimidad. (CID, 2012, p.129)
}

O carácter circulante e dinâmico dado às informações revela um ponto positivo para esta nova elaboração teórica, entretanto, não parece refletir a longitude e profundidade necessárias para uma elaboração teórica.

\section{CONCLUSÃO}

A dinâmica da sociedade e o advento de novas tecnologias exigem do Direito uma constante atualização. Os velhos conceitos devem ser revistos, abrigando novas perspectivas. O indivíduo expandiu suas fronteiras, de modo que vivemos, hoje, também num espaço virtual. Nesta medida, nossa privacidade ganha novos contornos. As teorias que desenham os 
âmbitos em que desenvolvemos nossa personalidade se veem impulsionadas a adotar noções mais flexíveis, moldáveis às circunstâncias; onde as informações devem ser contextualizadas com a totalidade de elementos que estão em jogo. Podemos, assim, vislumbrar duas necessidades que emergem. A primeira se refere à existência de uma legislação que proteja, de modo eficiente, os dados pessoais e, deste modo, também preserve a privacidade/ intimidade dos cidadãos. O Brasil está atrasado nesta tarefa. Países como Espanha, Alemanha, Canadá são bons exemplos de avanço. A regulamentação e a sistematização são muito importantes para darmos um passo em direção à tutela total do indivíduo no âmbito virtual. Existe, no Congresso, um Projeto de Lei de Proteção de Dados que tem essa pretensão (PL n. 181 de 2014).

Entretanto, se por um lado temos a indispensabilidade de uma legislação específica sobre a matéria, do outro, e na mesma medida de importância, temos a premência de uma construção teórica que dê substrato à ciência e que nos permita elaborar uma conceituação cada vez mais clara sobre a privacidade. Além disso, urge que compreendamos a nova realidade em que vivemos. Não há mais como voltar atrás. Estamos em uma via de mão única em que as inovações tecnológicas se sucedem a uma velocidade sem igual. A proteção à privacidade aos dados no contexto virtual representam desafios importantes neste novo cenário. As novas construções teóricas devem incorporar essa nova dinâmica das relações impostas pela presença dos meios digitais. É preciso abrir espaço à reflexão. É preciso voltar a pensar tudo novamente.

\section{REFERÊNCAS}

ARAÚJO, José L. Intimidade, vida privada e direito penal. São Paulo: WVC Editora, 1998. Pág. 44.

BAUMMAN, Zygmund. Modernidade Líquida. São Paulo: Zahar, 2001.

BRASIL. Constituição (1988). Constituição da República Federativa do Brasil. Brasília, DF: Senado Federal: Centro Gráfico, 1988.

BRASIL. Tribunal de Justiça do Distrito Federal e Territórios. Reclamação n. 001203511.2009.807.0000. $1^{\text {a}}$ Turma Criminal. Relatora: Des. Sandra de Santis. Brasília, 29/10/2009. BVerfGE 80,367, 373. 
CARO, Maria Álvarez. Derecho al Olvido en Internet: el nuevo paradigma de la privacidad en la era digital. Madrid: Reus, 2014, p. 51.

CID, Isabel Victoria Lucena. La protección de la intimidad en la era tecnológica: Hacia una reconceptualización. Revista internacional de pensamiento político-Ed. Época - Vol. 7 2012 - [117-144] - ISSN 1885-589x. Disponível em: <pensamientopolitico.org/Descargas/ RIPP07117144.pdf>. Acesso em: $1^{\circ}$ mar. 2015.

CID, Isabel V.I. (2014) El Concepto de la intimidad en los nuevos contextos tecnológicos. Em Alfonso Galán Muñoz (coord.) La protección jurídica de la intimidad y de los datos de carácter personal frente a las nuevas tecnologias de la información y comunicación. (p. 15-54) Valencia: Tirant.

CONESA, F. Derecho a la intimidad, informática y Estado de Derecho. Valencia: Universidad, 1984, pp. 44-45

COSTA JR., Paulo José da, O Direito a estar só: tutela penal da intimidade. São Paulo: RT, 1995, p. 30

CUEVA, Pablo Lucas Murillo de la. Informática y protección de datos personales. Madrid: Centro de Estudios Constitucionales, 1993, p. 69-70.

DI FIORE, B. H. Teoria dos círculos concêntricos da vida privada e suas repercussões na praxe jurídica. São Paulo: Editorial, 2012, p. 04. Disponível em: <03/012/2015.http://www. flaviotartuce.adv.br/index2.php?sec=artigosc\&totalPage=2>. Acesso em: 02 mar 2016.

DONELA, Danilo. Da privacidade à proteção de dados pessoais. Rio de Janeiro: Renovar, 2006.

GARZÓN VALDÉS, 2003: Algunos comentarios sobre lo íntimo, lo privado y lo público, em: Claves de razón práctica, n. ${ }^{\circ}$ 137, pp. 14-24.

GASSET, José Ortega Y. Obras Completas. Tomo 5. Madrid: Alianza, 1994. p. 301-302.

GUERRERO, Manuel Medina. La protección Constitucional de la Intimidad frente a los medios de comunicación. Tirant. Valencia: 2005.

http://economia.uol.com.br/impostoderenda/duvidas-frequentes/receita-federal-usacruzamento-de-dados-paratentar-evitar-fraudes-no-ir.jhtm

LARA, J. Carlos. La privacidad desde la perspectiva del Ordemaniento Chileno.

Disponivel em: <https://www.derechosdigitales.org/wp-content/uploads/pp-08.pdhtf>. Acesso em: 12 mar 2016.

LOMBARTE, R . Artemi e outros. Hacia un nuevo Derecho de Protección de Datos. Tirant. Madrid. 2015. Pag 67.

PÉREZ LUÑO, A. E. Los derechos humanos en la sociedad tecnológica. Madrid: Universitas, 2012. Pág. 91 
PITT, William. Speech on the Excise Bil. En: HANSARD, T. C. The Parliamentary History of England from the Earliest Period to the Year 1803, vol. 15.London: p. 1307. Disponível em: https://books.google.es/books?id=k7cTAAAAYAAJ\&printsec=frontcover\&hl=ptBR\& source=gbs_ge_summary_r\&cad=0\#v=onepage $\& q \& f=$ false. Acesso em: 10 Jan. 2016.

PROSSER, William. “Privacy”. California Law Review. Vol.48, p. 383,1960.

SERRANO, V. A proteção constitucional da informação e o direito à crítica jornalística. São Paulo: FTD, 1997.

STC 170/1987, FJ 4.

STC 292/2000, FJ 6.

TALCIANI, H. C. Definición Jurídica del derecho a la privacidad: concepto ydelimitación. En: Revista Chilena de derecho. Vol 27 No. 2. Santiago: Chile Editorial, 2000.

TERRA. Notícias. Tecnologia. Se seu carro tem um GPS, sabemos o que você faz, diz vice da Ford. 09 jan. 2014. Disponível em: <http://tecnologia.terra.com.br/se-seu-carro-tem-um-gpssabemos-o-que-voce-faz-dizvice-da-ford,06b2bb1c55a73410VgnVCM20000099cceb0aR CRD.html>. Acesso em: 05 Fev. 2016.

Vide Ley de Protección Organica de Tratamiento Automatizado de Datos de Caracter Personal, la Ley 5 de 1992, de 29 de octubre, en su apartado I.

VIEIRA, T. M. Direito à privacidade na sociedade informacional. Brasilia: UNB, 2007.

WARREN, S. D.; BRANDEIS, L. D. El derecho a la intimidad. Madrid: Editorial, 1995. Pág. 196.

XIV Encuentro sobre informática y Derecho 2000- 2001, Madrid- Elcano, Universidad Pontifícia de Comillas-Aranzadi, 2001- M.A. Davara Rodríguez, coord.- pag 48-49. 